\title{
193 nm Laser Photoionization and Photodissociation for Isomer Differentiation in Fourier-Transform Mass Spectrometry
}

\author{
Evan R. Williams and Fred W. McLafferty \\ Chemistry Department, Baker Laboratory, Cornell University, Ithaca, New York, USA
}

\begin{abstract}
Energetic $(6.4 \mathrm{eV})$ multiphoton ionization (MPI) or photodissociation, effected interchangeably in a Fourier-transform mass spectrometer, can differentiate isomers that yield similar electron ionization spectra. Selectivity is shown for isomers of $\mathrm{C}_{7} \mathrm{H}_{8}, \mathrm{C}_{7} \mathrm{H}_{9} \mathrm{~N}, \mathrm{C}_{7} \mathrm{H}_{7} \mathrm{~F}, \mathrm{C}_{8} \mathrm{H}_{10}$, but not of $\mathrm{C}_{6} \mathrm{H}_{3} \mathrm{Cl}_{3}$ and $\mathrm{C}_{14} \mathrm{H}_{10}$. The contrasting MPI fragmentations and ionization efficiencies, as well as high sensitivities, are of substantial analytical utility. The high ionization efficiency makes possible high resolution MPI spectra, such as 470,000 (FWHH) for the molecular ion of anthracene, from a single laser pulse. (J Am Soc Mass Spectrom 1990, 1, 361-365)
\end{abstract}

$\mathrm{P}$ romising applications of lasers to mass spectrometry [1] include multiphoton ionization (MPI) and ion photodissociation. This article describes complementary analytical applications for both of these using a $193 \mathrm{~nm}$ ArF laser with Fourier transform mass spectrometry (FTMS). Multiphoton ionization has been used extensively for probing the structure of gas phase molecules [1-5]. Using a wavelength in resonance with an accessible electronic state of the molecule can give high isomeric or even isotopic selectivity [1-12]. Such ionization efficiencies can approach $100 \%[4]$ as absorption of the second photon causes excitation to the continuum of preionization states. The internal energy of the molecular ion thus produced is often below the dissociation limit, making resonant two-photon ionization an efficient method for producing stable molecular ions. Metastable dissociations, resulting from photoexcitation to energies just above the dissociation barrier, can enhance differences in MPI mass spectra of isomers [6,7]; for this the greater-than-millisecond lifetimes of FTMS can be advantageous. Subsequent absorption of one or more additional photons produces higher energy ion dissociation, so that adjusting the power density or wavelength of the laser controls the extent of fragmentation and thus the utility of the resulting structural information. Power densities necessary for efficient MPI are best achieved with pulsed lasers; because obtaining a complete mass spectrum from a single laser pulse requires multichannel recording, MPI is typically used with time-of-flight mass spectrometry (TOFMS) [2-12] and, more recently, ion trap mass spectrometry [13] and FTMS [14-16]. Fourier-transform mass spectrom-

Address correspondence to Fred W. McLafferty, Chemistry Department, Baker Laboratory, Cornell University, Ithaca, NY 14853-1301. etry has the advantages of much higher resolution and unusual capabilities for tandem mass spectrometry (MS/MS) [17-20]. For example, using $266 \mathrm{~nm}$ photons, Carlin and Freiser [15] demonstrated the selectivity of MPI/FTMS for a variety of compounds absorbing at this wavelength, such as the high $(21,000)$ resolution MPI spectrum of azulene. Sack et al. [16] demonstrated $\sim 5$ ppm mass measuring accuracy and a resolution of 87,000 for gas chromatography/MPI FTMS of naphthalene. Sherman et al. [18] showed that $248 \mathrm{~nm}$ MPI can give ionization efficiencies thirty-five times that of electron ionization (EI).

For FTMS/MS, photodissociation is an attractive alternative to collisionally activated dissociation because this method is more compatible with the FTMS low pressure requirements for high resolution and sensitivity [19-21]. Infrared or visible wavelength photodissociation is useful for isomeric differentiation, but this produces only fragmentations of low activation energies $[22,23]$. Photodissociation using the $193 \mathrm{~nm}$ ArF excimer laser offers the advantage that its $6.42 \mathrm{eV}$ photons have sufficient energy for most structurally useful ion dissociation [24]; with these using FTMS, Bowers et al. [25] found ion dissociation efficiencies of up to 60\%, and also demonstrated MS/MS/MS. Hunt et al. [26] have shown that this technique is applicable to larger (up to $m / z$ 3100) ions, such as those from peptides.

A recent report of similar results [27] utilizes an FTMS experimental configuration permiting the 193 nm laser to be used conveniently for either or both MPI and photodissociation (efficiencies approaching $100 \%)$, as well as for desorption ionization. We report here that the use of $193 \mathrm{~nm}$ photons for MPI as well as for photodissociation appears to offer advantages of selectivity, sensitivity, and flexibility for isomer dif- 


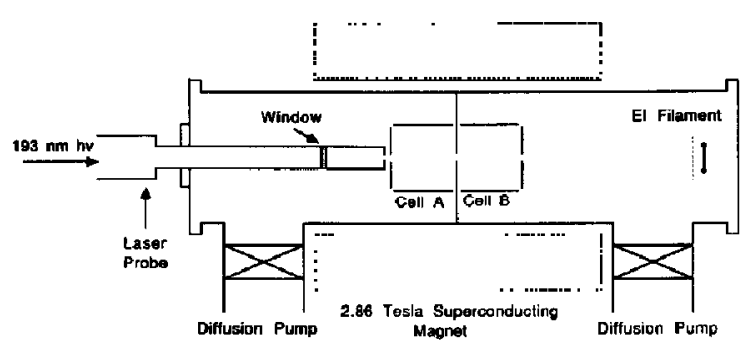

Figure 1. Schematic of photoionization/photodissociation FTMS instrument.

ferentiation even without the use of a tunable laser or supersonic sample cooling [10].

\section{Experimental}

The prototype dual-cell Nicolet FTMS-2000 (Figure 1) was operated at $2.86 \mathrm{~T}$ magnetic field and $3 \mathrm{~V}$ trapping potential, with $32 \mathrm{~K}$ data-point spectra. The $193 \mathrm{~nm}$ photons were provided by a Lambda Physik model 101 ArF excimer laser for the high power spectra $\left(\sim 5 \times 10^{7}\right.$ watts $/ \mathrm{cm}^{2}$ ) shown (Figures 2-4) or a Lumonics series TE-861S excimer laser for the low power spectra $\left(\sim 5 \times 10^{6}\right.$ watts $\left./ \mathrm{cm}^{2}\right)$, with energies of 30 and $3 \mathrm{~mJ}$, respectively, per $14 \mathrm{~ns}$ pulse focused to a $\sim 1 \times 5 \mathrm{~mm}^{2}$ spot at the ion cell entrance. The light reached cell $\mathrm{A}$ through an $\mathrm{MgF}_{2}$ window in a hollow probe (also used for backside laser desorption) [27] terminated by a 2$\mathrm{mm}$ hole aligned to minimize light striking the $2-\mathrm{mm}$ conductance limit between cells. Cell B was used for both sample introduction $\left(\sim 2 \times 10^{-7}\right.$ torr) and analysis in the single cell mode [28] for greater ion yield. A

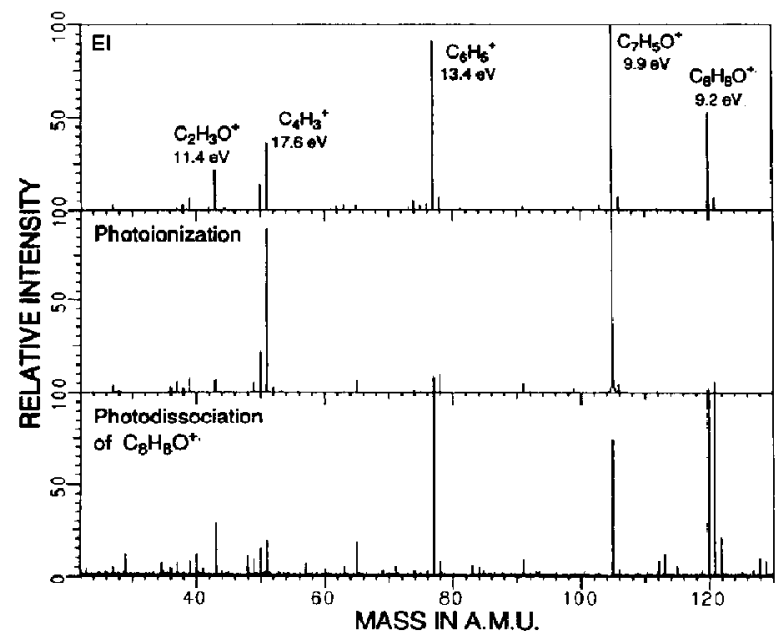

Figure 2. Acetophenone spectra: (top) El, (middle) MPI, and (bottom) photodissociation of the EI molecular ion. Numerical values are ionization and appearance energies [29]; $\mathrm{C}_{4} \mathrm{H}_{3}^{+}$value is that for benzene.

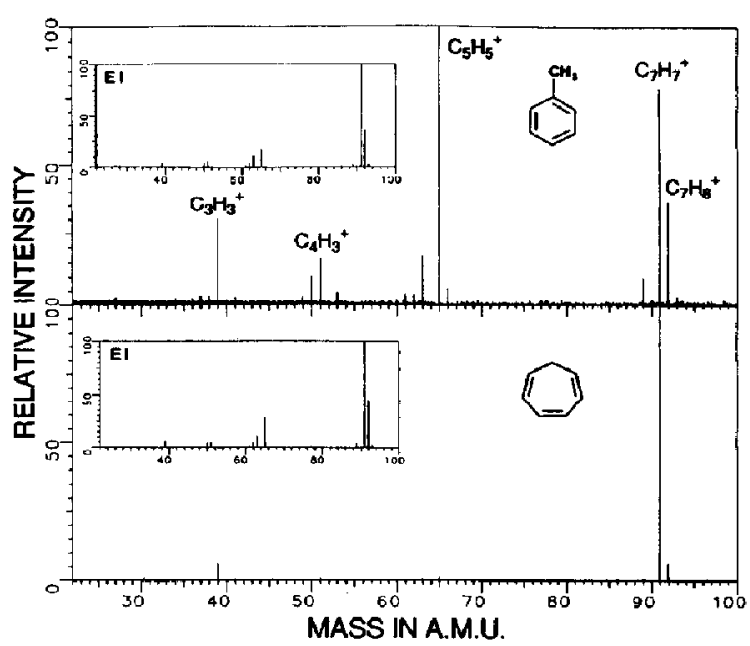

Figure 3. MPI spectra: (top) toluene and (bottom) cycloheptatriene. Insets: corresponding EI spectra.

background spectrum, including that from light striking the cell, was subtracted from the measured spectrum. Higher resolution spectra were measured in cell A $\left(\sim 2 \times 10^{-8}\right.$ torr) after momentarily dropping the conductance limit potential to zero to allow ions to pass between the two cells [29]. Long ( $10 \mathrm{~ms})$ ion transfer times resulted in complete signal loss due to misalignment of the laser with the magnetic field lines; the transfer times of 60-300 $\mu$ s used have the disadvantage that ion transfer was mass dependent. The $\mathrm{C}_{14} \mathrm{H}_{10} \mathrm{MPl}$ spectra were measured in an elongated cell $[30,31]$ made by removing the conductance limit and connecting the corresponding excite and receive plates of cells $A$ and $B$; the probe-end light restrictor was increased to a 6-mm diameter, increasing the photon flux in the cell

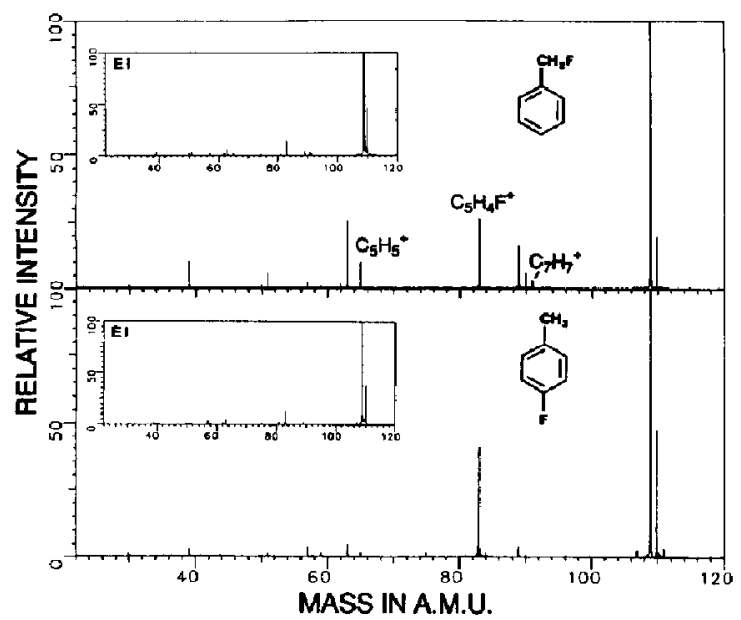

Figure 4. MPI spectra: (top) $\alpha$-fluorotoluene and (bottom) $p$ fluorotoluene. Insets: corresponding EI spectra. 
by $\sim 3 \times$. Photodissociation measurements used cell $\mathrm{A}$ in the dual cell mode with ionization by $70 \mathrm{eV}, \sim 3.5$ $\mu \mathrm{A}$ electrons. The desired parent ion, after selection by ejecting all other ions, was dissociated using a single laser pulse.

\section{Results and Discussion}

In this experimental configuration using a single excimer laser, the ions are formed by MPI in the same path along the magnetic field axis as that of the laser beam used for photodissociation of these ions (Figure 1). This optimizes the sensitivity of the photodissociation spectra, yielding signal/noise approaching that of the MPI spectra (Figure 2).

Acetophenone illustrates the complementary fragmentations that can result from these two uses of the $193 \mathrm{~nm}$ photons (Figure 2). Relative to the EI spectrum, photoionization greatly increases the abundance of $\mathrm{C}_{7} \mathrm{H}_{5} \mathrm{O}^{+}$and $\mathrm{C}_{4} \mathrm{H}_{3}^{+}$, while photodissociation increases that of $\mathrm{C}_{6} \mathrm{H}_{5}^{+}$. Two $6.4 \mathrm{eV}$ photons are required to ionize acetophenone, depositing a maximum of 12.8 $\mathrm{eV}$ into the molecule. This is greater than the $9.9 \mathrm{eV}$ appearance energy (AE) of $\mathrm{C}_{7} \mathrm{H}_{5} \mathrm{O}^{+}$[32], enhancing its abundance while reducing that of the molecular ion in comparison to the EI abundance. Although $12.8 \mathrm{eV}$ is lower than $\operatorname{AE}\left(\mathrm{C}_{6} \mathrm{H}_{5}^{+}\right)$, the latter is far below the energy of three photons $(19.2 \mathrm{eV})$, which provide sufficient energy for formation of $\mathrm{C}_{4} \mathrm{H}_{3}^{+}$, in line with its increased abundance versus the EI peak. In the photodissociation spectrum of the molecular ions, which initially must have internal energies $<0.7 \mathrm{eV}(9.9-9.2)$, deposition of $6.4 \mathrm{eV}$ favors $\mathrm{C}_{6} \mathrm{H}_{5}^{+}(\mathrm{AE}=13.4 \mathrm{eV})$ and $\mathrm{C}_{2} \mathrm{H}_{3} \mathrm{O}^{+}(11.4 \mathrm{eV})$ formation, the other common EI fragment ions of low abundance in the MPI spectrum. Higher energy photodissociation products result from the absorption of more than one photon. Under these conditions, the relative ion yields of EI ( 5 - ms beam) versus MPI (14-ms beam) are roughly equal, as estimated using $m / z 120$ (corrected for $\sim 2 \%$ photodissociation indicated by $m / z 77$ ) for EI and $m / z, 105$ for MPI.

$\mathrm{C}_{7} \mathrm{H}_{8}$ isomers. Cycloheptatriene and toluene have similar EI spectra (Figure 3), but their MPI spectra have dramatically different fragmentation patterns and ionization efficiencies. $\mathrm{AE}\left(\mathrm{C}_{7} \mathrm{H}_{7}^{+}\right)=10.0 \mathrm{eV}$ for cycloheptatriene, $1.6 \mathrm{eV}$ below that for toluene, consistent with the absence of $\mathrm{C}_{7} \mathrm{H}_{8}^{+\cdot}$ from the former $(\mathrm{m} / \mathrm{z}$ 92 is mainly ${ }^{12} \mathrm{C}_{6}{ }^{13} \mathrm{CH}_{7}^{+}$). Although the $12.8 \mathrm{eV}$ twophoton energy is $1.2 \mathrm{eV}$ above $\mathrm{AE}\left(\mathrm{C}_{7} \mathrm{H}_{7}^{+}\right)$of toluene, the rate of this threshold dissociation is reduced because it corresponds to the formation of the lower energy tropylium ion from cycloheptatriene molecular ions produced by rearrangement [33]. The threephoton process $(19.3 \mathrm{eV})$ accounts for the abundant $\mathrm{C}_{5} \mathrm{H}_{5}^{+}$from toluene $(\mathrm{AE}=16.7 \mathrm{eV})$; the dramatically greater amount than from cycloheptatriene, despite its nearly identical value of $\operatorname{AE}\left(C_{5} \mathrm{H}_{5}^{+}\right)$, could be due to absorption of the third photon by either a metastable toluene molecular ion or a benzyl ion a few nanoseconds after formation.

The total MPI ion yield for cycloheptatriene was $\sim 31$ times that of toluene with power densities $\sim 5 \times 10^{6}$ watts $/ \mathrm{cm}^{2}$, determined using the relative ion abundances resulting from mixtures of $d_{8}$ toluene/cycloheptatriene and $d_{8}$-toluene/toluene. Under higher power $\left(\sim 5 \times 10^{7}\right.$ watts $\left./ \mathrm{cm}^{2}\right)$, this relative yield decreased to $\sim 15 \times$. These ratios are much higher than that of $\sim 3$ for the one-photon absorption coefficients at $193 \mathrm{~nm}$ [34]; however, the much higher density of states in $S_{0}$ of toluene should lead to more rapid excited state relaxation after absorption of a single photon [35]. Aromatic molecules with substituents such as $\mathrm{CH}_{3}$ or $\mathrm{NH}_{2}$ have low quantum yields indicative of short-lived excited states that undergo rapid radiationless relaxation $[11,22]$. Increasing the power enhances the probability of absorption of a second photon before relaxation, thereby greatly enhancing the ion yield for toluene.

$\mathrm{C}_{7} \mathrm{H}_{9} \mathrm{~N}$ isomers. The EI spectra of 0 -toluidine and Nmethyl aniline (IP $=7.4$ and 7.3, respectively) [32] are similar, but again the MPI spectra show significant differences (Table 1). $[\mathrm{M}-\mathrm{H}]^{+}$is the base peak in the EI spectra of both isomers $(\mathrm{AP}=9.2$ and $11.0 \mathrm{eV}$, respectively) [32], but in the MPI spectrum of a-toluidine the base peak is $\mathrm{C}_{6} \mathrm{H}_{5}^{+}$(loss of $\mathrm{CH}_{4} \mathrm{~N}^{-}$), whose AP should be closer to that of the $12.8 \mathrm{eV}$ two-photon energy. The $\mathrm{C}_{6} \mathrm{H}_{8}^{+}$peak (loss of $\mathrm{CHN}$ ) is far more characteristic of $o$-toluidine in its MPI spectrum, being forty times more abundant than in the MPI spectrum of the other isomer. The photodissociation spectra also show significant differences, especially in the increased degree of dissociation of $\mathrm{N}$-methyl aniline, shown by peaks such as $m / z 65,55,51,50$, and 39 .

$\mathrm{C}_{7} \mathrm{H}_{7} \mathrm{~F}$ isomers. Slight differences are observed in the EI spectra of $\alpha$ - and $p$-fluorotoluene (Figure 4). Multiphoton ionization formation of $[\mathrm{M}-\mathrm{H}]^{+}$favors $\alpha$-fluorotoluene (AP $=11.9 \mathrm{eV}$ ) over that for $p$ fluorotoluene $(A P=12.2 \mathrm{eV})$. Multiphoton ionization also enhances the peaks in the $\alpha$-fluorotoluene spectrum at $m / z 65\left(\mathrm{C}_{5} \mathrm{H}_{5}^{+}\right)$and $91\left(\mathrm{C}_{7} \mathrm{H}_{7}^{+}\right)$that indicate fluorine on the methyl group. Multiphoton ionization also increases the abundance of $\mathrm{C}_{5} \mathrm{H}_{4} \mathrm{~F}$ for $p$-fluorotoluene, consistent with aromatic fluorine attachment.

$\mathrm{C}_{8} \mathrm{H}_{10}$ isomers. Takenoshita et al. [5] reported MPI spectra of $o$ - and $p$-xylene as a function of laser power at both 193 and $248 \mathrm{~nm}$, finding the main isomeric differences to be higher $m / z 91 / 106$ and 54/77 ratios for the o-isomer. Our data (Table 2) support this, but show additionally that all three xylene isomers are much more easily distinguished by their MPI than their EI spectra. At lower power where two and three photon processes dominate, the highest abundance at $m / z 65$ is the $o$-isomer, at $m / z 77$ is the $m$-isomer, and at $m / z 106$ is the p-isomer. At high power, $\mathrm{C}_{3} \mathrm{H}_{3}^{+}$formed by a 
Table 1. EI, MPI, and photodissociation spectra of $o$-toluidine and N-methyl aniline

\begin{tabular}{|c|c|c|c|c|c|c|}
\hline \multirow[b]{2}{*}{$m / z$} & \multicolumn{3}{|c|}{$a$-Toluidine } & \multicolumn{3}{|c|}{$\mathrm{N}$-methylaniline } \\
\hline & EI & MPI & PD & El & MPI & PD \\
\hline 107 & 64. & 29. & & 67. & 43. & \\
\hline 106 & 100 & 52. & 100. & 100 & 100 & 61. \\
\hline 92 & $<0.2$ & $<0.2$ & $<1$ & 2.4 & 3.5 & $<5$ \\
\hline 91 & 5.7 & 2.0 & 1.2 & 1.5 & 1.5 & 10. \\
\hline 89 & 7.8 & 7.0 & $<1$ & $<0.2$ & $<0.2$ & $<5$ \\
\hline 80 & 4.9 & 7.9 & 5. 1 & 3.2 & $<0.2$ & $<5$ \\
\hline 79 & 21. & 4.7 & 34. & 49. & 3.4 & 78. \\
\hline 77 & 22. & 100. & $<1$ & 35. & 63. & $<5$ \\
\hline 65 & 2.3 & 7.7 & 4.6 & 13. & 19. & 41. \\
\hline 63 & 3.8 & 12. & 3.9 & 7.7 & 9.2 & 15. \\
\hline 55 & 4.7 & $<0.2$ & $<1$ & 13. & $<0.2$ & 30. \\
\hline 51 & 9.2 & 24. & 7.5 & 26. & 51. & $9 b$. \\
\hline 50 & 6.7 & 22. & $<1$ & 15. & 44. & 46. \\
\hline 49 & 0.9 & 12. & $<1$ & 1.7 & 22. & $<5$ \\
\hline 41 & 4.9 & 4.8 & 5.6 & 10. & $<0.2$ & $<5$ \\
\hline 39 & 12. & 69. & 24. & 28. & 91. & 100. \\
\hline 36 & & 41. & $<1$ & & 99. & $<5$ \\
\hline 28 & 2.8 & 40 & 3.4 & 6.0 & 11. & $<5$ \\
\hline 27 & 4.9 & 51. & 5.1 & 6.6 & 16. & 30. \\
\hline
\end{tabular}

Abbreviations: $\mathrm{El}=$ electron ionization; $\mathrm{MPI}=$ multiphoton ionization; $\mathrm{PD}=$ photodissociation.

four-photon process [5] is the base peak in each of the spectra, with smaller isomeric differences in abundance of $m / z 65,77$, and 91 formed by three, three, and two photons, respectively.

$\mathrm{C}_{6} \mathrm{H}_{3} \mathrm{Cl}_{3}$ isomers. The EI spectra of 1,2,5-trichlorobenzene and 1,2,4-trichlorobenzene are indistinguishable, as are their MPI spectra. Loss of $\mathrm{d}$, the most abundant fragmentation pathway in the EI spectrum, does not appear in the MPI spectrum, whose most abundant peak represents the higher energy loss of $\mathrm{HCl}_{2}$.

$\mathrm{C}_{14} \mathrm{H}_{10}$ isomers. The $193 \mathrm{~nm}$ MPI spectra of anthracene, phenanthrene (Figure 5), and diphenylacetylene are poorly distinguishable and similar to their EI spectra in exhibiting little fragmentation. The $12.8 \mathrm{eV}$ of two photons is substantially below the appearance potentials for $\mathrm{C}_{14} \mathrm{H}_{8}{ }^{+\cdot}(\sim 17.4 \mathrm{eV})$ and $\mathrm{C}_{12} \mathrm{H}_{8}{ }^{+\cdot}$ (16.1 $\mathrm{eV}$ for diphenylacetylene). Similar results were reported for MPI spectra using 266 and $275-290 \mathrm{~nm}$ [4], consistent with $\mathrm{M}^{+} \cdot$ ion isomerization to a common structure [36], although 100-fold MPI discrimination of anthracene and phenanthracene can be achieved using resonant absorption at 310 and $285 \mathrm{~nm}$, respectively, of the first photon [37].

However, for these isomers $193 \mathrm{~nm}$ MPI did show a distinct asset. The relative ion yield using low laser power is $\sim 50$ times that of EI. Figure 5 compares the spectrum of phenanthracene from a 5 -ms electron beam with that from a single 14-ns laser pulse. The lack of $\mathrm{N}_{2}^{+}$or $\mathrm{O}_{2}^{+}$in the MPI spectrum is due to their relatively poor absorption at this wavelength. Multiple laser shots produced little additional fragmentation; the low cross section for ion absorption, relative

Table 2. EI and low power MPI spectra of $o_{-}, m-$, and $p$-xylene ${ }^{a}$

\begin{tabular}{rccccccc}
\hline$m / z$ & 0 & $m$ & $p$ & 0 & $m$ & $p$ \\
\hline \hline 106 & 35. & 36. & 37. & 14. & 19. & 22. \\
105 & 11. & 11. & 14. & 3.7 & 4.7 & 4.9 \\
91 & 100. & 100. & 100. & 100. & 100. & 100. \\
77 & 13. & 12. & 12. & 20. & 45. & 21. \\
65 & 10. & 8.6 & 8.3 & 20. & 19. & 12. \\
51 & 9.9 & 8.5 & 11. & 1.8 & 3.0 & 1.7 \\
39 & 12. & 12. & 11. & 3.1 & 4.6 & 3.0 \\
\hline
\end{tabular}

a Standard deviation < $\mathbf{1 . 5}$.

Abbreviations: See Table 1. 


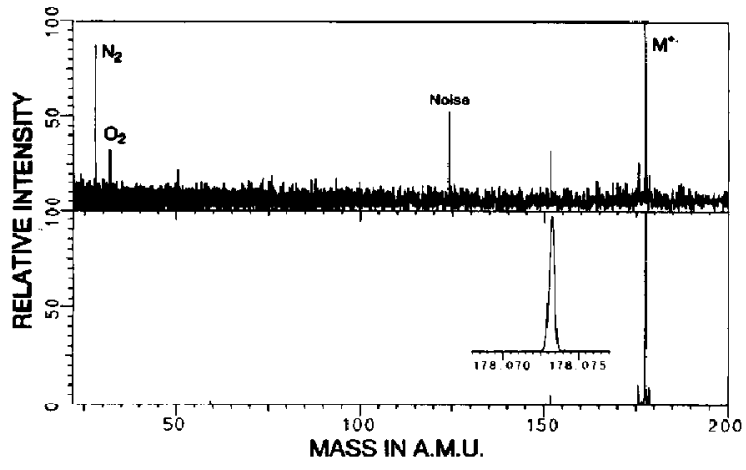

Figure 5. Single measurement of phenanthrene $\left(5 \times 10^{-9}\right.$ torr $)$ by (top) EI ( 5 -ms beam) and (bottom) MPI (14 ns pulse). Inset: molecular ion with $470 \mathrm{~K}$ (FWHH) resolution.

to that of the neutral mulecule, makes possible much higher efficiency of $\mathrm{M}^{+}$production with increased power densities. A single laser shot produces sufficient anthracene molecular ions to obtain a resolution of 470,000 , even without making the measurement on the low pressure side of a dual cell configuration.

\section{Conclusions}

Although $193 \mathrm{~nm}$ photons are too energetic to show large isomeric differences in the absorptivity of a single photon with small wavelength variations, their MPI and photodissociation spectra can be used to differentiate isomers that have similar EI spectra. Selectivity is observed in relative ionization efficiencies and fragmentation pathways, with the latter favored whose AP values are a little lower than the energies of the absorbed photons. The FTMS experimental configuration optimizes the sensitivity for photodissociation of ions produced by MPI as well as desorption ionization [27].

\section{Acknowledgments}

The authors wish to thank J. J. P. Furlong, J. A. Loo, and R. O. Loo for their encouragement and helpful advice, Perkin-Elmer for sponsorship of an American Chemical Society Analytical Division Fellowship (for ERW), the National Institutes of Health (grant GM16609) for generous financial support, and the $\mathrm{NIH}$ and the National Science foundation (grant (HE-8616907) for instrumentation.

\section{References}

1. Cotter, R. J. Anal. Chem. 1984, 56, 485A.

2. Lubman, D. M. Mass Spectrom. Rev. 1988 7, 535-554, 559-592.

3. Seaver, M.; Hudgens, J. W.; DeCorpo, J. J. Int. J. Mass Spectrom. Ion Phys. 1980, 34, 159-173. Bernstein, R. B. J. Phys. Chem. 1982, 86, 1178-1184.

4. Lubman, D. M; Kronick, M. N. Anal. Chem. 1982, 54, 660-665

5. Takenoshita, Y.; Shinohara, H.; Umemoto, M.; Nishi, N. Chem. Phys. Lett. 1982, 87, 566-569.

6. Kinsel, G. K.; Johnston, M. V. Anal. Chem. 1988, 60, 2084-2089.

7. Neussur, H. J. Int. J. Mass Spectrom. Ion Proc. 1987, 79, 141-181.
8. Grotemeyer, J.; Schlag, E. W. Angew. Chem. Int. Ed. Engl. $1988,27,447-459$.

9. Gobeli, D. A.; Yang, J. J.; El-Sayed, M. A. Chent. Reo. 1985, $85,529-554$.

10. Lubman, D. Anal. Chem. 1987, 59, 31A-40A.

11. Sin, C. H.; Tembreull, R,; Lubman, D. M. Anal. Chem. 1984, $56,2776-2781$.

12. Opsal, R. B.; Reilly, J. P. Anal. Chem. 1988, 60, 1060-1065.

13. Louris, J. N.; Amy, J. W.; Ridley, T. Y.; Kascheres, C.; Cooks, R. G. 35th Annual Conference on Mass Spectrometry and Allied Topics, Denver, CO, May 1987, pp 769-770.

14. Irion, M. P.; Bowers, W. D.; Hunter, R. L.; Rowland, F. S.; McIver, R. T., Jr. Chem. Phys. Lett. 1982, 93, 375-379.

15. Carlin, T. J.; Freiser, B. S. Anal. Chem. 1983, 55, 958-959.

16. Sack, T. M.; McCrery, D. A.; Gross, M. L. Anal. Chem. 1985, $57,1290-1295$.

17. McLafferty, F. W., Ed. Tandem Mass Spectrometry; John Wiley: New York, 1983. Busch, K. L.; Glish, G. L.; McLuckey, S. A. Mass Spectrometry/Mass Spectrometry; VCH: New York, 1989.

18. Sherman, M. G.; Kingsley, J. R.; Hemminger, J. C.; Mclver, R. T., Jr. Anal. Chim. Acta 1985, 178, 79-89.

19. Allemann, M.; Kellerhals, H. P.; Wanczek, K.-P. Int. J. Mass Spectrom. Ion Phys. 1983, 46, 139-142. White, R. L.; Ledford, E. B., Jr.; Ghaderi, S.; Wilkins, C. L.; Gross, M. L. Anal. Chem. 1980, 52, 1525-1527.

20. Buchanan, M. V., Ed. Tandem Fourier-Transform Mass Spectrometry; American Chemical Society: Washington, DC, 1987.

21. Cody, R. B. Anal. Chem. 1988, 60, 917-923.

22. Dunbar, R, C. In Gas Phase Ion Chemistry; Bowers, M. T., Ed.; Academic: Orlando, FL, 1984; Vol. 3, Chapter 20.

23. van der Hart, W. J. Mass Spectrom. Rev. 1989 8, 237-268. Baykut, G.; Watson C. H.; Weller, R. R.; Eyler, J. R. J. Am. Chem. Soc. 1985, 107, 8036-8042.

24. McLafferty, F. W. Interpretation of Mass Spectra, 3rd ed.; University Science Books: Mill Valley, CA, 1980.

25. Bowers, W. D.; Delbert, S.-S.; Mclver, R. T. Anal. Chem. 1986, 58, 969-972. Lebrilla, C. B.; Wang, D. T.-S.; Mizoguchi, T. J.; McIver, R. T. J. Am. Chem. Soc. 1989, 111, 8593-8598.

26. Hunt, D. F.; Shabanowitz, J.; Yates, J. R. III J. Chem. Soc. Chem. Commun. 1987, 548-550. Hunt, D. F.; Shabanowitz, J.; Yates, J. R. III; Griffin, P. R.; Zhou, N. Z. Anal. Chim. Acta 1988, in press.

27. Loo, J. A.; Williams, E. R.; Furlong, J. J. P.; Wang, B. W.; McLafferty, F, W. 35th Annual Conference on Mass Spectrometry and Allied Topics, Denver, CO, May 1987, 727-728. Williams, E. R.; Furlong, J. J. P.; McLafferty, F. W. I. Am. Soc. Mass Spectrom., accepted.

28. Comisarow, M. B. Adv. Mass Spectrom. 1980, 8, 1697-1706.

29. Ghaderi, S.; Littlejohn, D. P. Adv. Mass Spectrom. 1986, 10, 875 .

30. Hunter, R. L.; Sherman, M. G.; McIver, R. T., Jr. Int. J. Mass Spectrom. Ion Phys. 1983, 50, 259-274.

31. Williams, E. R.; McLafferty, F. W. J. Am. Soc. Mass Spectrom,, accepted.

32. Rosenstock, H. M.; Draxl, K.; Steiner, B. W.; Herron, J. T. J. Phys. Chem. Refer. Data 1977, 6, Suppl. 1.

33. McLafferty, F. W.; Bockhoff, F. J. Am. Chem. Soc. 1979, 101, 1783-1786.

34. Astholtz, D. C.; Brouwer, L.; Troe, J. Ber. Bunsenges. Phys. Chen. 1981, 85, 559-564.

35. Jacobson, B. A.; Guest, J. A.; Novak, F. A.; Rice, S. A. J. Chem. Phys, 1987, 87, 269-283.

36. Pachuta, S.; Kenttamaa, T.; Sack, T.; Cerny, R.; Tomer, K.; Gross, M.; Pachuta, R.; Cooks, R. G. J. Am. Chem. Soc. 1988, 110, 657-665.

37. Klimcak, C. M.; Wessel, J. E. Anal. Chem. 1980, 52, 1233-1239. 